[2] Krause M, Refshauge KM, Dessen M, et al. Lumbar spine traction: evaluation of effects and recommended application for treatment. Manual therapy 2000;5:72-81.

[3] Harte AA, Gracey JH, Baxter GD. Current use of lumbar traction in the management of low back pain: results of a survey of physiotherapists in the UK. Archives of physical medicine and rehabilitation 2005;86:1164-9.

[4] Fritz JM, Lindsay W, Matheson JW, et al. Is there a subgroup of patients with low back pain likely to benefit from mechanical traction? Results of a randomized clinical trial and subgrouping analysis. Spine 2007;32:E793800 .

Disclosure of Interest: None declared

DOI: 10.1136/annrheumdis-2018-eular.1244

\section{THU0540 INCREASED WORK CAPACITY IN CHRONIC LOW BACK PAIN PATIENTS AFTER A MULTIDIMENSIONAL PROGRAM ASSOCIATED WITH DECREASE IN FEAR AND APPREHENSION}

M. Norberg ${ }^{1,2}$, L. Belgrand ${ }^{2} .{ }^{1}$ Rehabilitation, Centre medical et therapeutique La Lignière, Gland; ${ }^{2}$ Rehabilitation, Lavey Medical SA, Lavey Les Bains, Switzerland

Background: Chronic low back pain has a high burden in our society. Almost $85 \%$ of he population would be affected from low back pain. Less than $10 \%$ would be chronic but they have an important economic impact since they have the highest costs. According to Vlayen, the kinesiophobia (avoidance of movement) is the most important prognostic factor when evaluating the return to work

Objectives: To study the importance of kinesiophobia, fear and anxiety in the chronic low back (CLB) pain patient and their relationship to workability after a multidimensional intensive treatment program.

Methods: We included 850 patients who had followed an outpatient program of functional restoration during 3 weeks. The program was composed of physical exercises, occupational therapy and psychological group discussions. They were followed over 1 year. Using different questionnaires (TSK -Tampa scale of Kinesiophobia, FABQ, Pact -subjective work capacity-, Phoda, SF 36), physical performances tests (muscular endurance: Shirado, Biering-Sörensen, Bruce; lumbar mobility, Pile lifting test) we analysed the important factors for their work capacity. Results: There were a clear relationship between a decrease in kinesiophobia and an increase of work capacity. Globally, the work capacity increased from $41.2 \%$ to $79 \%$. There were no long standing increases in muscular performances, but the important change appeared in the decrease in the physical part of $F A B Q$ (14 to $9 / 24$ ) and the SF36 limitations physical health/emotional problems $(19.4 \%$ to $51.8 \% / 36$ to $65.7 \%)$.

Conclusions: A multidimensional intensive program including approaches on fear and apprehension has an important impact on work capacity. This observation is important to take into count in creating functional restoration programs

Disclosure of Interest: None declared

DOI: 10.1136/annrheumdis-2018-eular.2887

\section{THU0541 \\ THE EFFECT OF PHYSICAL THERAPY ON CLINICAL AND QUALITY OF LIFE IN CHRONIC NECK PAIN PATIENTS:A RANDOMISED CONTROLLED TRIAL}

N. Şahin ${ }^{1}$, M. Şahin ${ }^{2} .{ }^{1}$ Physical Medicine and Rehabilitation, Balıkesir University, Balıkesir, ${ }^{2}$ Physical Medicine and Rehabilitation, Magnet Hospital, Kayseri, Turkey

Background: In the treatment of chronic neck pain (CNP), education, medical treatment, exercise and physical therapy (PT) modalities are in place. However, there are not enough studies on the efficacy of PT modalities in CNP

Objectives: To evaluate the effectiveness of the addiction of PT modalities to exercise and medical treatment in relieving pain and improving the funcitonal status of patient with CNP

Methods: 80 patients with CNP were included in a randomised, controlled trial. Patients were assigned in two groups randomly. Treatment group (TG) recieved convantional PT (hot pack (HP), ultrasound (US), Transcutaneous Electrical Nerve Stimulation (TENS)) treatment in addition.PT was applied ten sessions.HP treatment was applied in $20 \mathrm{~min}$.US treatment was applied with $1,5 \mathrm{watt} / \mathrm{cm}^{2} \mathrm{dose}$ and continuous type in $10 \mathrm{~min}$.TENS treatment was applied with conventional type in $30 \mathrm{~min}$. All patients were informed about correct posture and daily life activities. Both groups received home-based exercises program and analgesic medical treatment if it is necessary. Patients were evaluated before and after therapy and 3th month later by Visual Analogue Scale (VAS), cervical range of motion (ROM), Beck Depression Scale (BDS) and short form-36 (SF-36)
Results: In both groups there is significant improvement in VAS, cervical ROM, SF 36 and BDS after treatment $(p<0.01)$. In TG significant improvement was seen on 3th month follow up. But the significant improvement was not seen on 3th month in control group (CG).

There is no significant difference between groups for VAS, SF-36 parameters and BDS before and after treatment ( $p>0.05)$. There was a significant improvement in VAS, SF-36 parameters and BDS in the TG compared with the CG at the end of therapy and 3 months post-treatment $(p<0.01)$

Conclusions: Medical treatment and exercise with HP, US and TENS therapy was effective on both pain and disability during the treatment. This improvement keep on 3th month follow up. Also same improvement was seen on mood and life qualty. Exercise has better effects on after treatment, but these goods effects decrease on 3th month follow up. So we think physical medicine modalities should be used in CNP with disability

\section{REFERENCES :}

[1] Binder A.The diagnosis and treatment of nonspecific neck pain and whiplash.Eura Medicophys 2007;43:79-89.

[2] Leaver AM, Refshauge KM, Maher CG, et al. Conservative interventions provide short-term relief for non-specific neck pain. J Physiother 2010;56:73-84

[3] Wang WTJ, Olson SL, Campbell AH, et al.Effectiveness of Physical Therapy for Patients with Neck Pain. A Individualized Approach Using a Clinical Decision-Making Algorithm. Am J Phys Med Rehabil 2003;82:203-218.

Disclosure of Interest: None declared

DOI: 10.1136/annrheumdis-2018-eular.2689

\section{THU0542 EVALUATION OF THE EFFECTIVENESS OF ULTRASOUND GUIDED EPIDURAL CORTICOSTEROID INJECTION AND PULSED ELECTROMAGNETIC FIELD STIMULATION IN CHRONIC LOW BACK PAIN}

S.A. Tabra ${ }^{1}$, M. ElSergany ${ }^{2}$, M.E. Mowafy ${ }^{1}$, H. Khallaf ${ }^{1}$, G. Elsharnopy ${ }^{3}$.

${ }^{1}$ Rheumatology and Rehabilitation, Faculty of Medicine. Tanta University;

${ }^{2}$ Rheumatology and Rehabilitation, Faculty of medicine Tanta university; ${ }^{3}$ clinical pathology, Faculty of Medicine. Tanta University, Tanta, Egypt

Background: Epidural injections are one of the most common nonsurgical interventions for managing chronic low back pain. They have been used to treat radicular pain from herniated discs, spinal stenosis, and axial spinal pain1. Pulsed electromagnetic field stimulation therapy (PEMFs) provides a noninvasive and safe method to treat the site of injury, the source of pain, inflammation by modulating factors involved in pain signalling and the inflammatory response2.

Objectives: - To assess the improvement in patients with chronic low back pain treated with epidural steroid injection or Pulsed electromagnetic field stimulation. To compare the efficacy of epidural steroid injection and pulsed electromagnetic field stimulation in treatment of patients with chronic low back pain.

Methods: In this study; sixty patients with chronic discogenic low back pain (diagnosed clinically and by magnetic resonant imaging of lumbosacral region) with or without radicular pain of at least 6 months duration were selected. We excluded patients with other causes of back pain as spondylolithesis, inflammatory, infective, neoplastic, traumatic causes. Patients were randomly divided into two equal groups (30 patients each); after informed consent; group I treated by ultrasound guided caudal epidural injection of $40 \mathrm{mg}$ methylprednisolone and $2 \mathrm{ml} 2 \%$ lidocaine and $20 \mathrm{ml}$ of $9 \% \mathrm{NaCl}$ twice one week in between and group II received PEMFs daily for 4 weeks. And all patients will be instructed to follow an exercise program. All patients were assessed clinically, functionally by Oswestry Disability Index (ODI) and by measuring serum level of beta-endorphin by ELIZA before, at the end treatment and six months after the end of treatment.

Results: In both groups; there was highly significant improvement in pain after treatment $(\mathrm{P} 1<0.0001)$ the mean value of the (VAS) was $8.13+0.63,7.70$ +1.34 respectively before treatment and $3.33+2.63,2.30+2.32$ respectively after treatment. Still further significant improvement at the end follow up ( $\mathrm{P} 1<0.0001)$ in group I. There was highly significant improvement $(p<0.0001)$ of functional status in both groups after treatment and at follow up period as compared to before treatment but there was significant decrease of functional status at follow up period as compared to after treatment in group II. There was significant improvement of serum level of beta endorphin ( $p>0.05$ ) In both groups after treatment and follow up period as compared to before treatment but there was insignificant difference at follow up period as compared to after treatment.. Our result showed insig nificant difference between two groups in clinical, functional or laboratory parameters. 


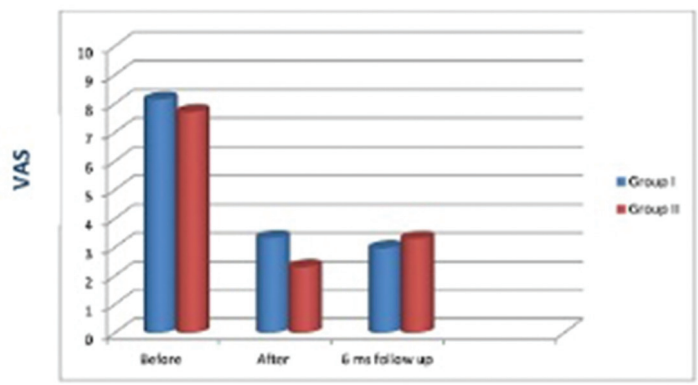

Figure 1. Comparison regarding low back pain as measured by VAS before, after treatment and at 6 months follow up

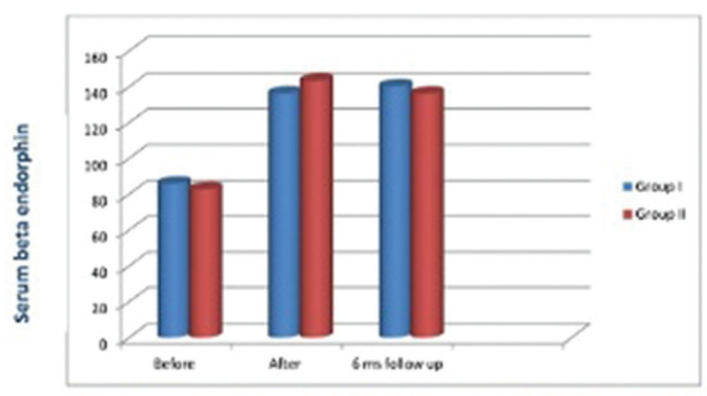

Figure 2. Comparison regarding serum beta endorphin before, after treatment and at 6 months follow up

Conclusions: Epidural corticosteroid injection and Pulsed electromagnetic field stimulation are effective tools in management of chronic low back pain

\section{REFERENCES:}

[1] Abdi S, Datta S, Trescot AM, et al. Epidural steroids in the management of chronic spinal pain: a systematic review. Pain Physician 2007;10(1):185212.

[2] Rohde C, Chiang A, Adipoju O, et al. Effects of pulsed electromagnetic fields on interleukin-1 beta and postoperative pain: a double-blind, placebo-controlled, pilot study in breast reduction patients. Plast Reconstr Surg 2010;125(6):1620-9

Disclosure of Interest: None declared DOI: 10.1136/annrheumdis-2018-eular.2069

\section{THU0543 COMPARISON OF THE EFFECTIVENESS OF LOW LEVEL LASER THERAPY AND STEROID INJECTION IN MODERATE CARPAL TUNNEL SYNDROME: A RANDOMISED CONTROLLED TRIAL}

S. Badıl Güloğlu ${ }^{1}$, M. Bilgilisoy Filiz ${ }^{1}$, K.K. Kılıç${ }^{2}$, S. Koldaş Doğann ${ }^{1}$, I. Erdem Toslak ${ }^{2}$, N.F. Toraman ${ }^{1} .{ }^{1}$ Physical Medicine and Rehabilitation; ${ }^{2}$ Radiology, Health Sciences University, Antalya Training and Research Hospital, Antalya, Turkey, Antalya, Turkey

Background: Recent studies have reported that low-level laser therapy (LLLT) reduces pain and improves function in carpal tunnel syndrome (CTS). However, to the best of our knowledge, there exist no studies that compares the effectiveness of LLLT and steroid injections in moderate CTS.

Objectives: Is to evaluate the effectiveness of LLLT and steroid injection in moderate CTS, by comparing the symptoms, the electrophysiologic and the Magnetic Resonance Imaging (MRI) findings of the patients.

Methods: 87 patients with moderate CTS were included in the study. 87 patients were randomised to the steroid or LLLT groups. LLLT was applied to the carpal tunnel area ( 6 joules $/ 5 \mathrm{~min}$ ) five times per week, for a total of 10 sessions. Steroid injections were performed once after randomization. Numbness and pain of the patients were assessed using a Visual Analogue Scale (VAS), disability was assesses using the Quick arm-shoulder-hand (Quick DASH) disability questionnaire. Rough and fine grasping strength tests, Tinel and Phalen tests and electrophysiological test were performed. All the patients were evaluated by MRI in terms of median nerve cross-sectional area, median nerve intensity and intensity rate, and median nerve palmary spring rate. All tests were performed before the treatment, and 1. month and 6. months after the treatment, except the MR evaluations, which were done before and after 6 . months of the treatment.

Results: The study was completed with 80 patients, 133 wrists at the end of six months. There were no significant differences between the groups in terms of dermographic and baseline clinic characteristics, electrophysiologic and MRI findings of the patients $(p>0,05)$. While the VAS scores of numbness and pain and Quick Dash symptom scores were better in the steroid group in the first month, there were no significant differences between the groups in the sixth month. In both groups, there were similar significant improvements in the Phalen and Tinel tests, rough and fine grasping forces, median nerve motor distal latency value in the first and sixth months after the treatment in comparison to pretreatment values $(p<0.05)$. Median nerve sensory distal latency and median sensory NCV showed significant improvements in the 1 st and the 6 th months after treatment in comparison to pretreatment only in the steroid group $(\mathrm{p}<0.05)$. In both groups, there were similar significant improvements in the median nerve intensity rate in the radioulnar plane and median nerve palmary spring rate on the MRI after the treatment. Median nerve intensity rate was improved in both groups also at the pisiform plane but this improvement was significant only in the steroid group.

Conclusions: It is possible to conclude that LLLT reduces the signs and symsptoms of the patients who has moderate CTS as well as the steroid treatment. Ou study offers a data regarding LLLT's efficiency in short-intermediate terms. Further studies are needed to make comments about long-term efficiency of LLLT. LLLT is a noninvasive treatment option in moderate CTS and with a similar efficacy as steroid treatment.

\section{REFERENCE:}

[1] Evcik D, Kavuncu V, Cakir T, Subasi V, Yaman M. Laser therapy in the treatment of carpal tunnel syndrome: a randomized controlled trial. Photomed Laser Surg 2007;25:34-39.

Disclosure of Interest: None declared

DOI: 10.1136/annrheumdis-2018-eular.4218

\section{THU0544 \\ STUDY OF THE EFFECTS OF OZONE VERSUS STEROID INJECTION ON PATIENTS WITH RECALCITRANT} TENNIS ELBOW; A CLINICAL TRIAL

S.A. Raeissadat ${ }^{1}$, M.H. Abdollahzadeh ${ }^{2} .{ }^{1}$ Physical Medicine and Rehabilitation Department of Shahid Beheshti University of Medical Sciences, Research Development Center of Shahid Modarres Hospital; ${ }^{2}$ Physical Medicine and Rehabilitation Department of Shahid Beheshti University of Medical Sciences, Physical Medicine and Rehabilitation Research Center, Tehran, Iran, Islamic Republic of Ireland

Background: Tennis elbow is a prevalent musculoskeletal disorder. In recent years ozone injection has been proposed as a treatment for many musculoskeletal disorders. This study aims to compare the effect of ozone injection with steroid in patients with recalcitrant tennis elbow.

Objectives: The aim of this study is to compare the effect of ozone with the standard treatment of steroid injection in patients with tennis elbow, resistant to conservative treatments. This comparison is made according to VAS score, Pressure pain threshold (PPT) and modified Mayo clinic performance index for elbow.

Methods: In this study 64 patients with tennis elbow, which have had the symptoms for more than 3 months and were resistant to conservative treatments, were randomised to two groups. In steroid injection group $40 \mathrm{mg}$ of methylprednisolone acetate and in zone injection group $4 \mathrm{ml}$ of ozone with concentration of $15 \mathrm{mcg} / \mathrm{ml}$ was injected. 32 patients in steroid and 29 patients in ozone injection group finished this study. Data were gathered before injection and 2 and 6 months after that by VAS score, modified Mayo clinic performance index for elbow and PPT (measured by the means of an algometer). Variables were compared between the two groups and also the changes in each group have been measured in reference to baseline data.

Results: In both groups VAS score, Mayo clinic performance index and PPT improved significantly in 2 and 6 month follow up. Steroid injection was significantly better than ozone injection in improving 2 and 6 months pressure pain threshold and 6 months Mayo clinic performance index. Other data didn't show significant difference between the two groups.

Conclusions: Both steroid and ozone injection improved pain and function in patients with recalcitrant tennis elbow for at least 6 months. Steroid injection was superior to ozone injection in improving PPT during the 2 and 6 month follow up and function improvement in steroid group was significantly more than ozone group after 6 month. 